\title{
Building Pandemic Resilience in Design: Space and Movement in Art Museums during Covid-19
}

\section{Chenyang Li, Sophia Psarra}

chenyang.li.19@ucl.ac.uk; s.psarra@ucl.ac.uk

Bartlett School of Architecture, UCL

\begin{abstract}
The global pandemic of COVID-19 has posed challenges in relation to how buildings re-open to use, particularly buildings attracting large numbers of visitors, such as museums and galleries. As these institutions start to reopen across the UK and internationally, a number of social distance measures have been adopted in order to safely bring people into their premises and access their collections. Building on Bill Hillier's theorical model of spatial types and spatial structures (2019), we explore the spatial-curatorial changes implicated in the reopening of four art museums (The National Gallery, The Tate Britain and Tate Modern in London) and one American museum (The MoMA, New York). Our purpose is not to provide practical solutions, but to set the search for spatial approaches to the re-opening of museums within a theory of spatial structure in space syntax theory and inform the design future of public buildings. We present a model of a three-layered spatial system interfacing the global and local structure of these buildings. We argue that the presence of intersecting cycles of movement in spatial layouts determines their capability for adapting to the one-way routes imposed by the pandemic. The spatial organisation of the display is a second factor influencing the reopening strategies, either limiting or optimising available spatial sequences to meet curatorial criteria.
\end{abstract}

Keywords: museums, structure types, traversability, space syntax, One-way routes; COVID19

\section{Introduction}

Despite placing many of their collections on line (Agostino et al, 2020), museums around the world have to reopen due to social, educational and economic pressures. One noticeable trend is the growing emphasis museum curators place on the influence of space on visitors' movement patterns. As Scott Stulen, CEO and President of the Philbrook Museum of Art, claims, 'the museum we closed will not be the museum we reopen (Stulen, 2020). Discussing questions emerging from the pandemic, Honey-Rosés et al. (2020) argue that there will be a clear change in people's behaviour in public spaces, mainly because their ability to interact with strangers is limited under the fear of infection. They suggest that social interactions in public spaces will be less spontaneous or informal. Their study proposes that, in the long-term, the requirement of social distance will change the scale and spatial arrangement of indoor facilities since the required distance (normally 2 meters) exceeds existing distances, as for example in the distribution of seats. Guidelines for the reopening of museums during the pandemic crisis specify instructions and interventions that are partly influenced by the spatial layout of buildings (Ellis and Szanto, 2020). Table 1 shows the rules applied for reopening by a number of museums in China, Britain and the UK. All these institutions have limited the number of visitors, reducing the visiting flows. However, only British museums have adopted one-way visiting routes in order to prevent people from reversing their paths crossing one another. Most of their Chinese and American counterparts tend to implement fixed

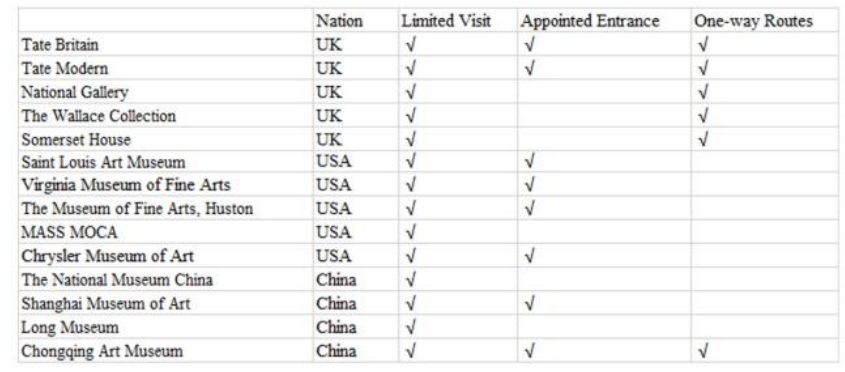

Table 1: Reopening strategies of museums in Britain, America and China. 
entrances and exits without changing the internal structure of circulation. It is important to note that although social distance is emphasized in all museums, on-site investigation carried out by our team shows that restrictions have not been well implemented. If discipline of behaviour is not always possible, the spatial layout becomes even more important in terms of exercising control over the exploration

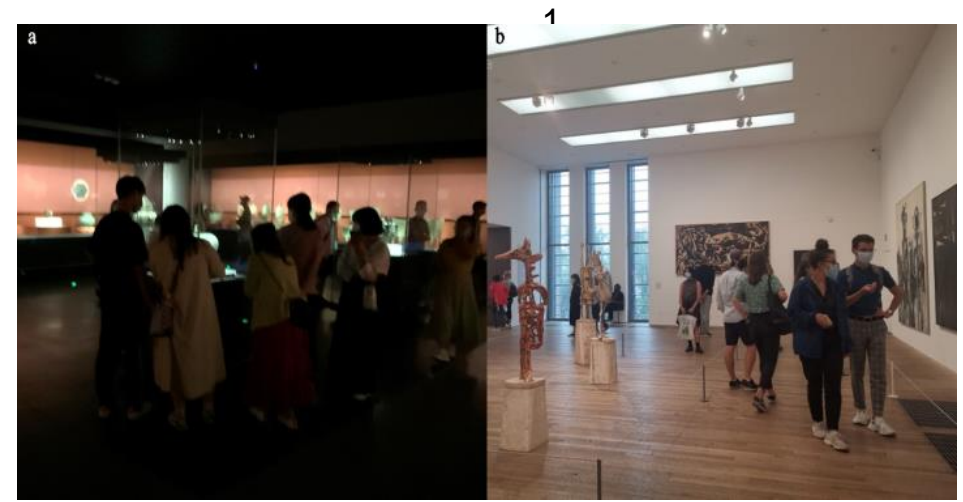

Figure 1: Photos taken after the reopening museums. (a) Hunan Provincial Museum, China; (b) The Tate Modern, UK

The greatest challenge for curators around the world is reopening their institutions to meet requirements for safety without sacrificing the spatial, social and educational experience. Most of the strategies used by museums concern practical solutions, specifying one-way circulation paths when distancing is possible, and blocking of spaces in case this is not feasible. But we have no means of assessing the spatial and cultural effect of strong differences in the spatial structure of galleries, for example the performance of a building as a whole in ways that makes it comparable to other buildings, and detect relations of global performance. This paper sets out to provide a syntactic examination of selected museums in order to comparatively describe their structure as a way of making clear their relations to each other, and perhaps their relations to a family of possible structures, or a model of spatial forms. In addition to this task, this study aims to answer the following questions: How does the original spatial layout of the selected museums affect the patterns of movement and circulation? What are the consequences of the spatial changes based on one-way route in the patterns of movement and the spatial culture of museums? Will there be a new spatial culture for museums that illustrates a new relationship between curators and visitors, influenced by the global pandemic?

\section{Spatial configuration and patterns of movement in museums and galleries}

Studies of spatial layouts using space syntax represent spatial layouts by means of permeability (and visibility) graphs. Figure 2a gives an example of a permeability graph drawn over the plan of the fifth floor galleries of the MoMA 2005 layout with a vertex representing each space and an edge connecting two spaces that are directly accessible. The diagram in Figure $2 b$ rearranges the graph without any changes to its topological structure, by representing the exterior (or the two entrances to the galleries) by a single vertex at the bottom of the figure and arranging all spaces that are directly accessible by each space on set levels (justified graph) (Hillier and Hanson, 1984). This graph enables the calculation of certain properties of the circulation network, in particular, topological mean depth in terms of the number of spaces to be traversed from each space to all other spaces. The normalised version of this measure is defined as the measure of integration (ibid.).
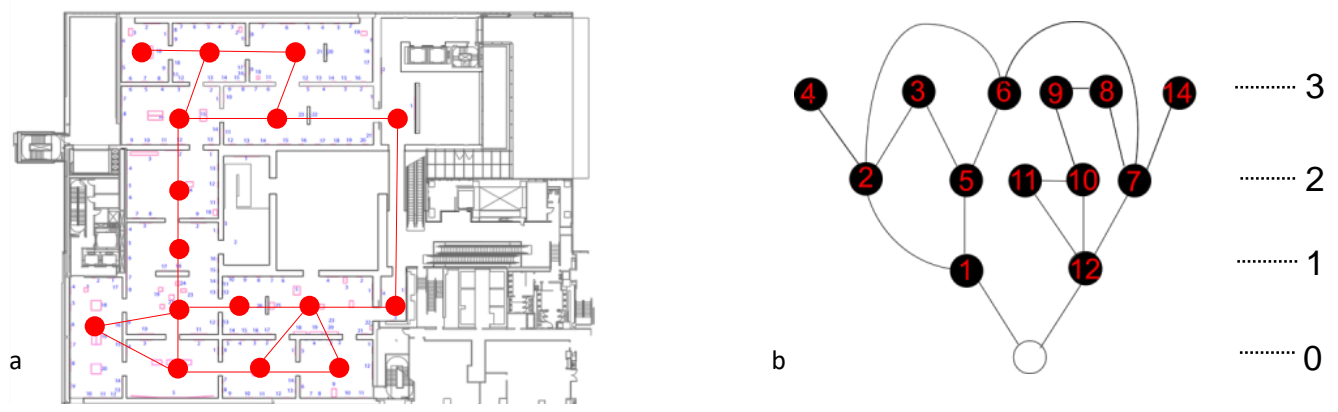

Figure 2 (a) MoMA New York, 2005, fifth floor galleries with superimposed graph; (b) justified graph of the same layout 
A crucial part of space syntax theory is the configurational properties of graphs describing each space in the graph in terms of how it relates to the entire system. For example, there are graphs when edges end in a point (rooms that have no through-movement) (Figure 3c). There are graphs that are like trees where there is only one path between any pair of vertices (Figure $3 \mathrm{~b}$ ) requiring to retrace one's steps in order to return to the space from where they departed. There are cycles where it is possible to set out and return to any vertex via a continuous ring of edges and vertices (Figure 3c). Finally there are intersecting cycles where it is possible to leave one room and return to it via more than one ring of circulation. Hillier's classification of graph arrangements (1996) identifies four space types each one associated with the above paths: dead-ends (a-type of space without through-movement); trees (b-type of space allowing through-movement but only the same way back); cycles (c-type offering one alternative way back) and intersecting cycles (d-type offering more than one alternative paths back). In his most recent research on graph arrangements (2019) he adjusted the definition of space types based on the number of spaces each space type is part of (from 1 to 4 ) and the number of through-movement connections from 0 to 3 . He also explained that space types generate emergent graph structures, structure-types, which can contribute to the development of a theoretical and analytical model for comparing spatial structures. By analysing the Tate Britain, he argues that it has a d-structure almost in every part of the layout. By comparing London's and Tokyo's street networks, he suggests that Tokyo has a d-structure of main arteries generating routes from all parts to all others, whereas London forms c-structures linking the centre with sub-centres. In the case of buildings, a d-structure such as that of the Tate Britain in Milbank, constructs a dense pattern of convergence and divergence of routes, producing a high rate or encounters and re-encounters of visitors as they browse through galleries, or what is called the 'churning effect' (ibid.).

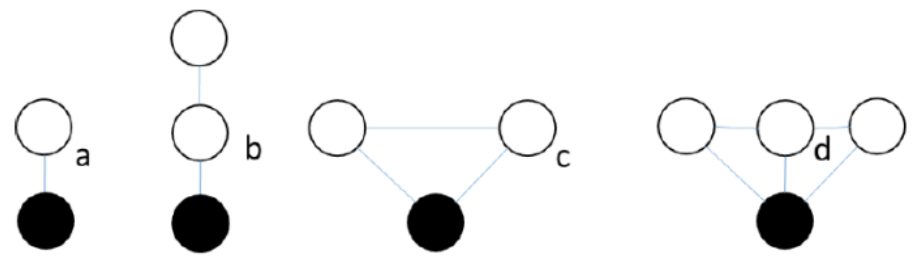

Figure 3 Space Types (Hillier 2019)

Extensive research using the space syntax method shows that, everything else being equal, there is a strong effect from the spatial structure and the distribution of integration-segregation on the patterns of movement and use in buildings, housing different institutional types, including museums and galleries (Hilllier et al, 1996; Choi, 1999; Huang, 2001; 2006; Hillier and Tzortzi, 2006; Koch and Stein 2012; Psarra 2009, Lazaridou and Psarra, 2015, 2017; Wineman and Peponis, 2010, Sailer and Penn, 2009). In a study of the Tate Britain, for example, strong correlations between spatial variables and data of human activity indicate a close relationship between the main circulation spine and the ways in which people move inside the building (Hillier et all, 1996; Tzortzi, 2007; Hillier and Tzortzi, 2006). The relationship between spatial configuration and the arrangement of displays using space syntax analysis also points to the key role space plays in organising collections through a synergistic relationship between spatial layout and display concept, structuring the museum visit (Peponis and Hedin, 1984; Psarra and Grajewski, 1999, Psarra et al 2007; 2009; Tzortzi, 2003; 2005; 2007; Stavroulaki and Peponis, 2003). Studies focusing of graph arrangements of layouts (Hillier and Tzortzi 2006; Capillé and Psarra 2013, Lazaridou and Psarra, 2013, 2015) show that a- and d- spaces strengthen the integration levels of layouts, while b- and c-spaces increase segregation, by encouraging through-movement. Further, the balance of c-spaces and d-spaces is the crucial factor influencing navigation and experience of visitors. If c-spaces make the majority of spaces in a layout, visitors, and consequently social encounters, are constrained to particular sequences. On the other hand, visitors have more spatial choice and are exposed to a more probabilistic pattern of social encounters in layouts consisting of a high number of d-spaces (Hillier, 2019).

In his 2019 study of graph structures, Hillier defines the measure of 'traversability' closely related to 'Hamiltonicity', a property in which 'there is a path (Hamiltonian path) visiting each space exactly once, and so neither repeating or omitting nodes, and ending up where you started. Traversability can be measured for a structure-type by dividing the total number of steps, including revisits, required to go from each node to all others by the minimum possible for that number of nodes, that is, when each step take you to a new node (2019). The value of traversability will be maximised if there are no revisits in the sequence of viewing spaces, 
and minimised if all the spaces need to be revisited. In this paper we calculate traversability looking at how many exhibition spaces need to be closed in order to achieve the Hamiltonian path -which could practically provide the required one-way circulation during the pandemic crisis - subtracting this number from the total number of spaces and dividing by the total number of spaces. By considering how the graph structure of the selected museums can accommodate the Hamiltonian path, we will assess their capacity to meet the requirements for safety without having to close a high number of exhibition spaces that compromises the cultural and educational experience.

A reasonable hypothesis is that the higher the value of traversability the easier a layout would seem to adapt to one-way route transformations. But how is it possible to compare the structure of different museums? As Hillier's model is based on theoretical graph structures and a single real-world building (The Tate Britain in Millbank), we use the four museums (12 layouts including all exhibition floors) his Hillier's theoretical model of c-structure and d-structure as the prerequisite for traversability.

\section{Analysis of the original and the transformed layouts}

Building on Psarra et al.'s work on the historical evolution of MoMA, New York, we first look at the newest expansion of the museum in 2019 and its previous layouts (Figures 4.1). We then investigate the layouts of the reopening of the National Gallery, the Tate Britain and Tate Modern, all of which have similar sizes (Figure 4.2). A small museum of a private collection, The Wallace Collection, provides another interesting case, allowing a comparison between spatial structures of different size.
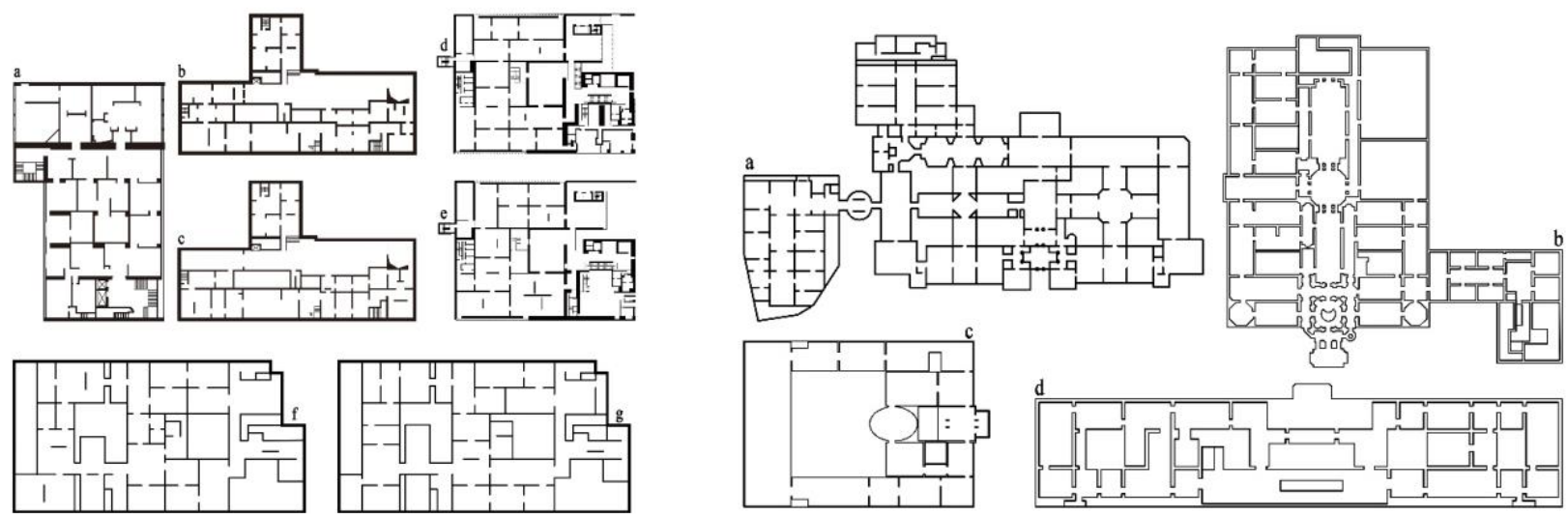

Figure 4.2: (a) the National Gallery ; b) Tate Britain; (c) the Wallace

Figure 4.1: Floor plans of the MoMA. (a) 1967; (b) 1986; (c) 1996 ;(d) 2005 Fifth floor; (e) 2005 Forth floor; (f) 2019 Collection; (d) Tate Modern

\subsection{The MoMA}

In 2019 the Museum of Modern Art (MoMA) in New York opened its expanded campus developed by architects Diller Scofidio + Renfro, in collaboration with Gensler, adding more than 40,000 square feet of gallery spaces. Compared with the museum's previous layouts (Psarra et al, 2007; Psarra, 2009), we see that the intersecting cycles of movement in the 2005 expansion are reduced to two large intersecting cycles, largely defining linear routes (Figure 5). There are only two sub-cycles on the south side of the fifth floor while both floors have a considerable number of a-spaces, that is, dead-end rooms. 

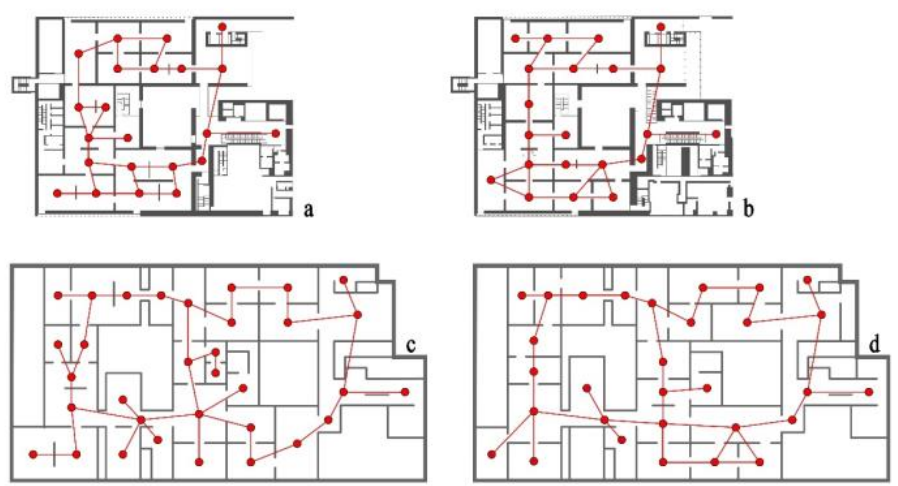

Figure 5: Unjustified graphs of the MoMA. (a) 2005 Fourth floor; (b) 2005 Fifth floor; (c) 2019 Fourth floor; (d) 2019 Fifth floor

We see that on the fourth-floor integration (shown in warm colours) is mainly located at the centre of the layout, posing challenges for way-finding and navigation, particularly on entering the galleries from the north and south entrances (Figure 6). On the fifth floor, integration connects the south entrance with the far west side of the layout. The galleries at the north and north-west remain strongly segregated on both floors (shown in cool colours). Popular displays recommended in the Museum map are placed either close to the north entrance or in the deepest parts of the layout. The curatorial strategy is based on the attraction exercised by the exhibition content as in most areas the structure of circulation cannot guide exploration.
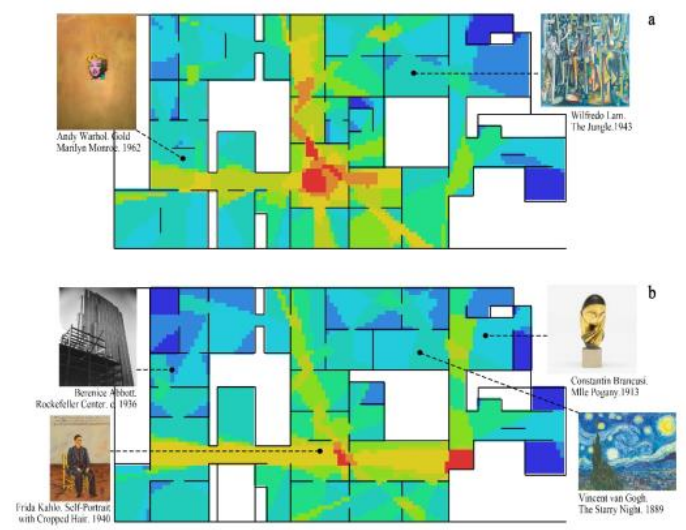

Figure 6: Visual integration of MoMA with target displays marked. (a) Fourth Floor; (b) Fifth floor

Figure 7 present the justified graphs and the space types of the MoMA from 1978 to 2019. Table 2 shows the proportion of spatial types in relation to the total number of spaces and the measure of traversability in the different periods of the MoMA's design. We see that the proportion of d-spaces increases from 1967 to 2005 at $22 \%$ and $42 \%$ respectively but decreases drastically in the latest expansion. The analysis shows that the measure of traversability follows a similar trajectory to that of d-spaces, first increasing (from 0.58 in 1967 to its highest value, $0.72 / 0.79$ in 2005 , in $4^{\text {th }}$ floor and $5^{\text {th }}$ floor respectively), and then dropping to its lowest figure (0.59) in 2019. These figures and the justified graphs illustrate a clear similarity between the latest expansion and MoMA's previous versions in the 20th century (1967, 1986 \& 1996), first, in terms of step depth from the entrance (from 8 steps in 1967 to 5 and 6 in 1997 and 2005 respectively, and finally to 10 in 2019); and second in terms of proportion of d-spaces. In order to provide a Hamiltonian path, nearly a half of spaces in the fourth and fifth floor of the new MoMA needs to be closed including those in the middle of the layout and the dead-end spaces on the sides (Figure 8).

We clarify that we use Hillier's 1996 definition of d-spaces identified by intersection of cycles offering more than one alternative way back. If we were to use the 2019 definition by Hillier, all spaces marked as d-paces (red colour) in the diagram are c-spaces (yellow) as the other rooms they link with through cycles do not have an alternative way back. 

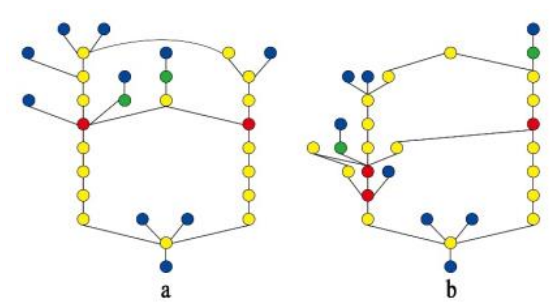

- a-space $\bigcirc$-space

c-space d-space
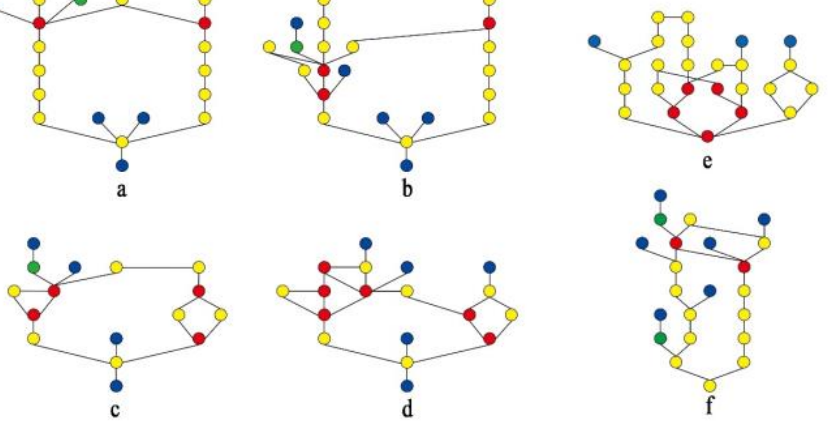

Figure 7: Justified graphs of the MoMA in different periods. (a) 2019 Fourth floor; (b) 2019 Fifth Floor; (c) 2005 Fourth Floor; (d) 2005 Fifth floor; (e) 1996; (f) 1978.
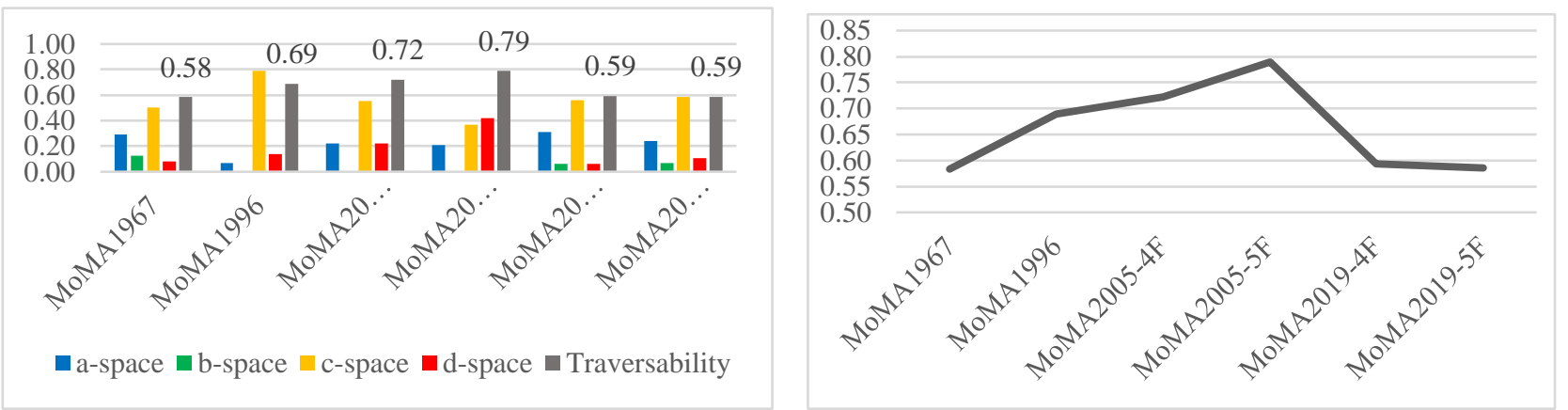

Table 2: Space types and traversability value of the MoMA over time

Table 3: Taversability of the MoMA in different periods
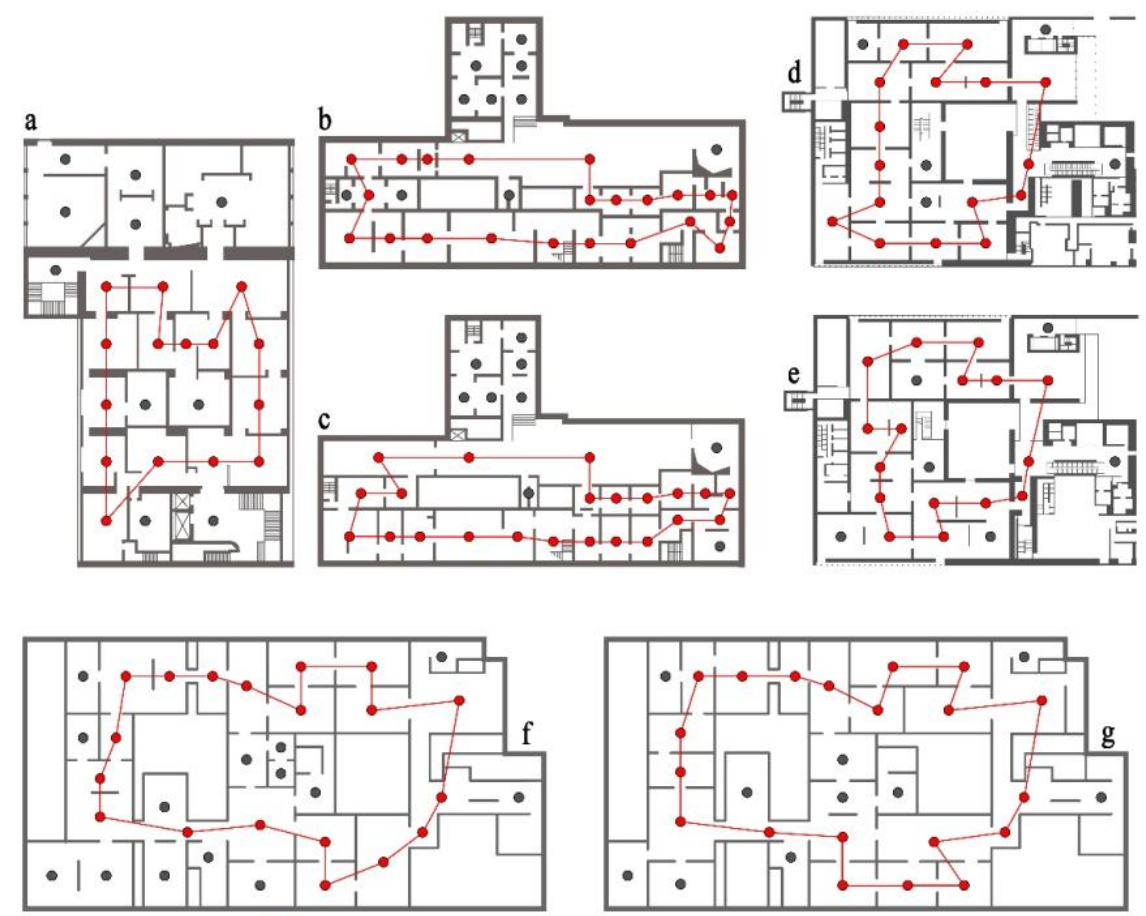

— Hamiltonian Cycle Spces within Hamiltonian Cycle Spces outside Hamiltonian Cycle

Figure 8: Hamiltonian cycle of MoMA. (a) 1967; (b) 1986; (c) 1996; (d) 2005 Fifth floor; (e) 2005 Forth floor (f); 2019 Fourth floor; (g) 2019 Fifth floor 


\subsection{The National Gallery}

Five one-way routes (and a small tree-like sequence) are used in the National Gallery after re-opening, one in the Sainsbury Wing and four others in the main building (Figure 9). In order to minimise the numbers of rooms that need to be closed, the three one-way routes in the main building are interconnected along the central east-west axis. The entrance and exit are arranged so that people enter through the Sainsbury Wing on the left and exit through the main building.

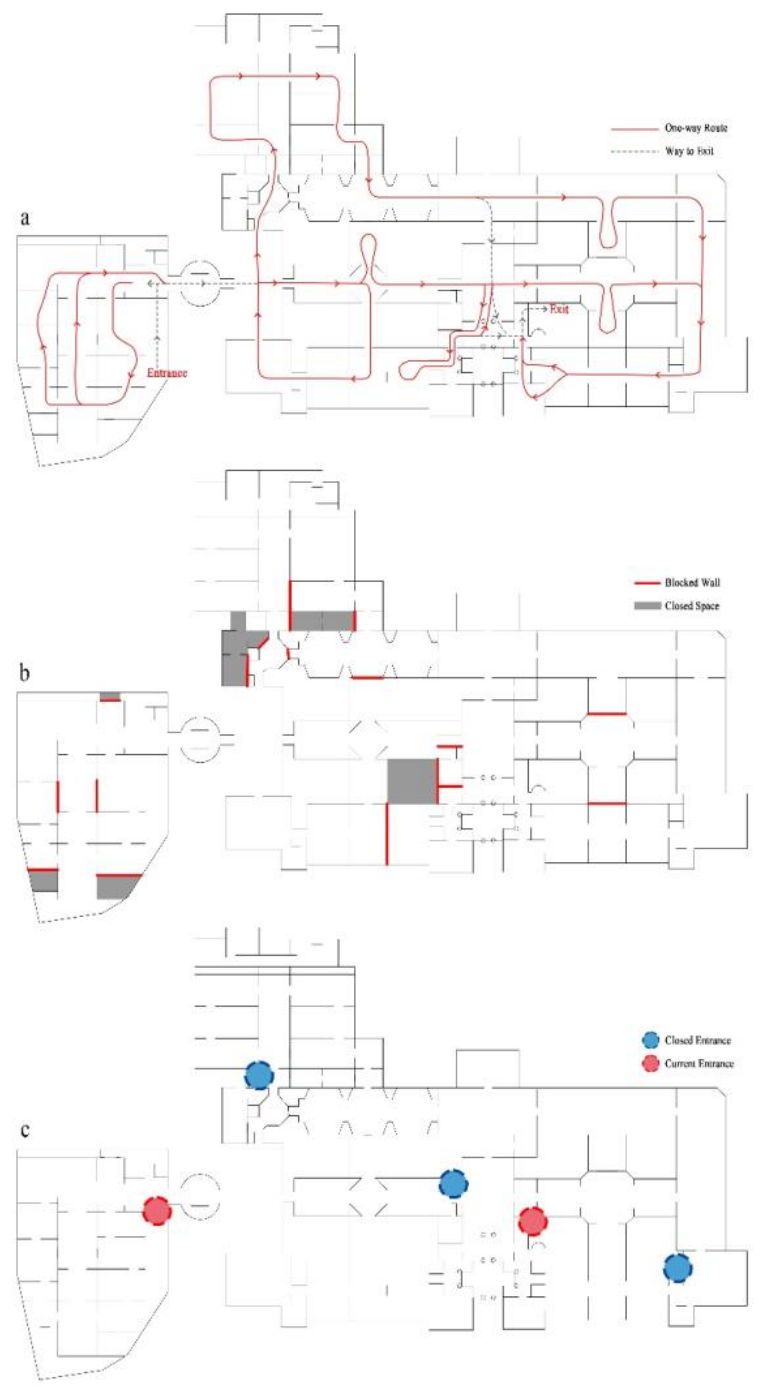

Figure 9: (a) One-way routes in the National Gallery; (b) Blocked doorways and rooms ;(c) entrances before + after the reopening

\subsubsection{The Sainsbury Wing}
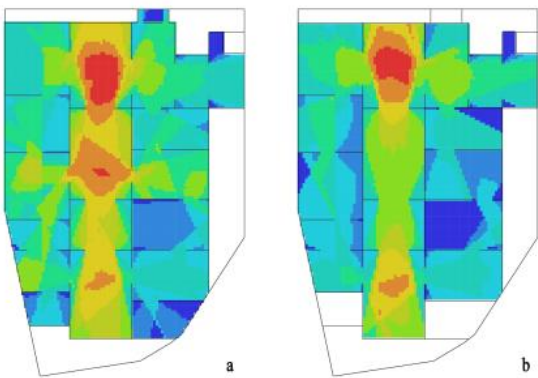

Figure 10: VGA of the Sainsbury Wing (a) before reopening; (b) after reopening.

In the Sainsbury's Wing several doorways connecting the central spine of rooms with the galleries on either side are closed, reducing the levels of integration, the lateral spread of integrated connections (Figure 10) the 
visual links to key paintings across galleries (Figure 11) and the number of $d$-spaces (Figure 12). The one-way pathway (Figure 9a) requires visitors to turn left immediately after entering the Wing and follow a linear route through segregated galleries to the front end of the layout (Figures 9a, 10b). They can then either cross to the west side and following another set of segregated rooms move in the opposite direction, or return through the central galleries back to the entrance. The one-way route, thus, does not follow the structure of circulation, taking people away from the most integrated areas, located at the centre of the plan, both at beginning the end of the visit.
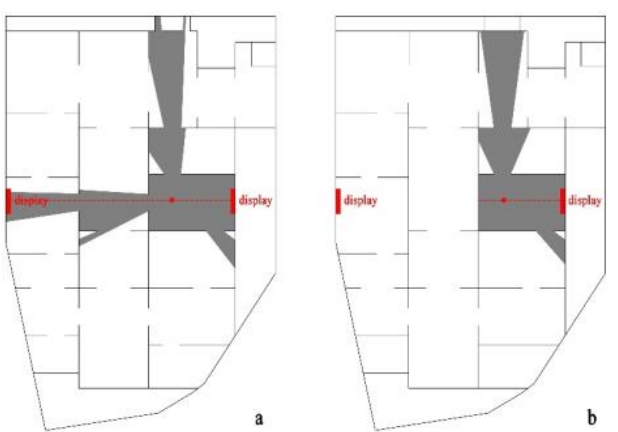

Figure 11: Isovists showing the lateral visual links connecting galleries and art work. (a) before reopening; (b) after reopening

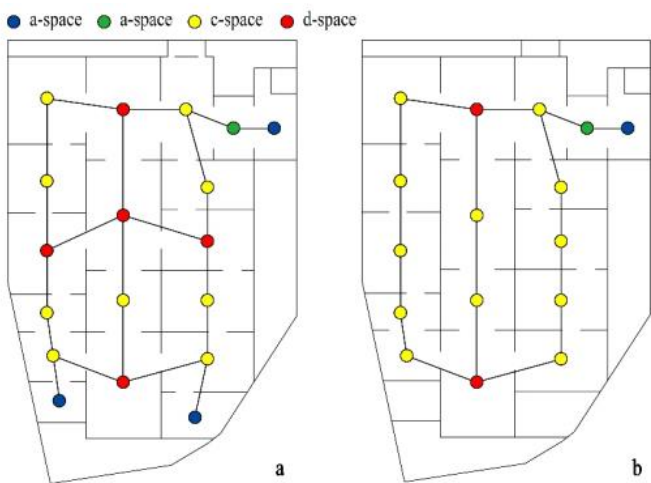

Figure 12: Unjustified graph of the Sainsbury Wing. (a) before reopening; (b) after reopening

\subsubsection{The main building}

The distribution of integration in the original building (Figure 13a) picks the intersections of the enfilade axes, forming a grid-like pattern of main centres and sub-centres (in red) that covers most spaces. There is a threepart structure consisting of the network of main centres, subsidiary centres and the rest of gallery rooms. The
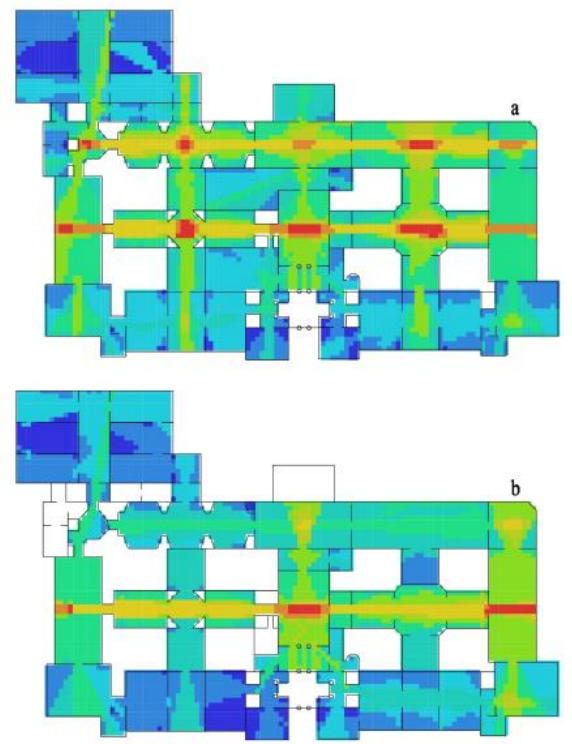

Figure 13: VGA of the National Gallery's main building. (a) before reopening; (b) after reopening 
main centres are located on the central axis organising movement towards sub-centres which in turn connect with the local spaces (Figure 6.9).

The reopening strategy shortens the two axial links located on either side of the central axis of the building. As a result, the distribution of integration that previously traversed the gallery rooms in grid-like pattern is limited to the east-west axis. The connections between the main centres and the sub-centres are thus cut by the blocked doorways (Figure 14). As the integration centres concentrate on the central east-west axis, there is also a considerable drop of the layout's intelligibility from 0.7024 to $0.5631\left(R^{2}\right)$ (Figure 15). The overall values of integration drop as does intelligibility. Defined as the ratio of connectivity to integration the measure of intelligibility capture the extent to which the number of local spatial connections of each room is a good informant of its position in the global structure of integration. The low levels of intelligibility in the National Gallery indicate that visitors are likely to find difficult to navigate the building.

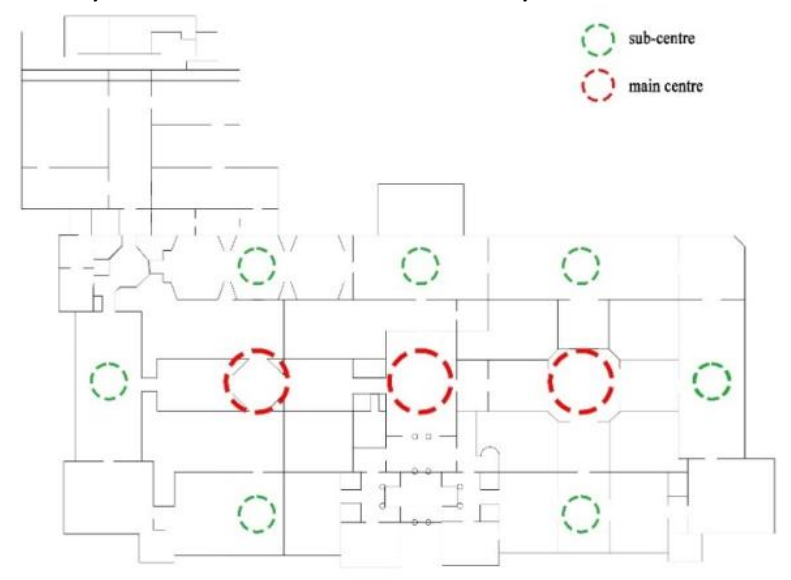

Figure 14: Main centres and sub-centres of the National Gallery's main building based on integration values
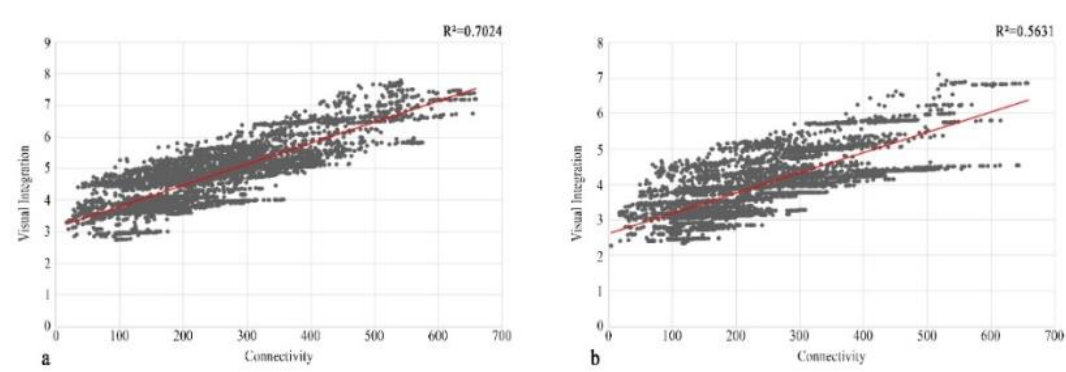

Figure 15: Visual intelligibility of the National Gallery's main building. (a) before reopening; (b) after reopening

Comparing the graph structures before and after the re-opening reveals a striking reduction of the proportion of $d$-spaces and a raise in the proportion of c-spaces from $47 \%$ to $72 \%$. It should be noted that the Gallery has blocked off four dead-end spaces for the reopening but has created five new ones spaces which changed from c-spaces to a-spaces because of the cut of connections. By re-connecting these spaces, (Figure 16c), the previous structure of $d$-spaces can be re-instated. This structure is still flexible for one-way paths as we will show in a later section. In addition, it restores the previous pattern of integration and even increases the degree of intelligibility to the $\mathrm{R}^{2}$ at 0.7353 . Therefore, other things being equal and transmission rates taken into account, it might not be a good option for the National Gallery to change spatial structure of the main building and give up the advantage it has by organising movement through the three-part network of centres.

Is then the one-way strategy a global solution for all museums despite difference in their spatial structure? There could be more appropriate approaches for reopening, for the National Gallery at least. Based on the experiment in Figure 16c, one possible strategy is to divide the visiting route into multiple sub-cycles dynamically organises by $d$-spaces. With higher levels of intelligibility and a more coherent spatial system, the museum would be less likely to see the congestion of visitors along the main axis where paths already intersect, which is also important for ensuring safety. 

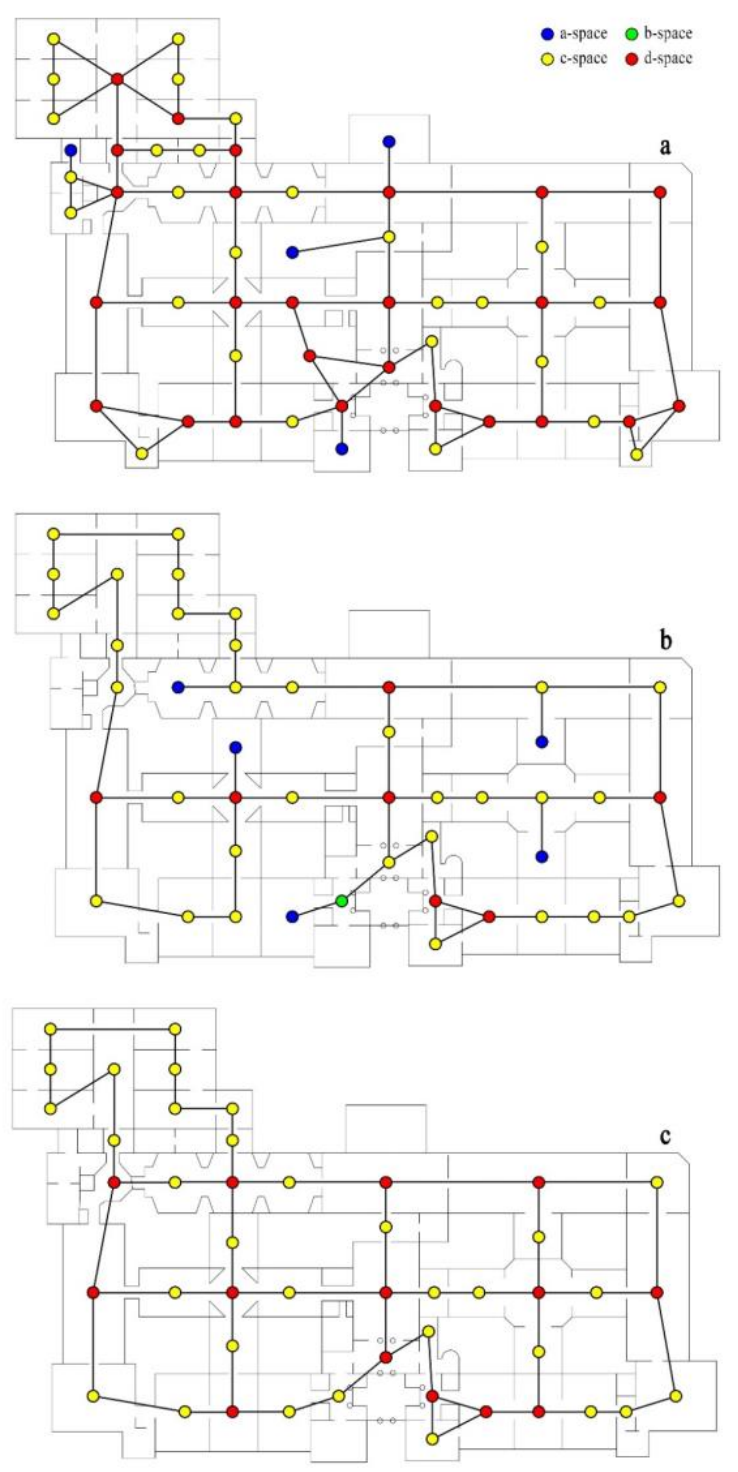

Figure 16: Unjustified graph of the National Gallery's main building, classifying spatial types by colour. (a) before reopening; (b) after reopening; (c) the experiment

\subsection{The Tate Britain}

The Tate Britain has implemented an one-way strategy by offering two routes, departing from and returning to the main axis of the building (Figure 17). The exhibition themes along these routes, 'British Art 1540-1890' (top-left) and 'British Art 1930- now'(bottom-right), follow a clear chronological narrative. A high proportion of doorways have been blocked changing the spatial structure of the layout from a d-structure (intersecting cycles) throughout the plan (Hillier, 2019) to two locally applied c-structures (cycles) (Figure 17a, b). It is not simply safety measures but also exhibition strategies informing the spatial changes in the building. For example, in order to maintain the chronological sequence of the display in the bottom-left route, the curators have closed more spaces that those needed to create a Hamiltonian path as seen in Figure 18. 

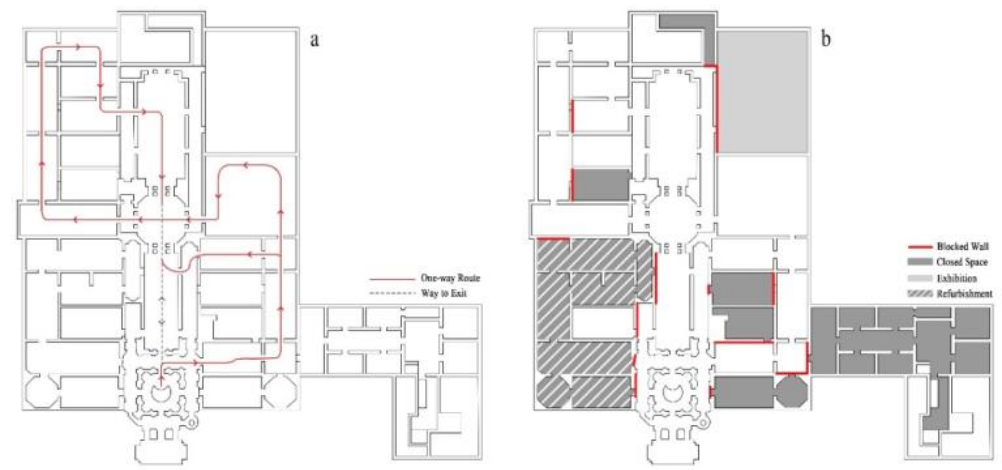

Figure 17a: One-way routes in Tate Britain; Figure 17b: Blocked doorways and rooms
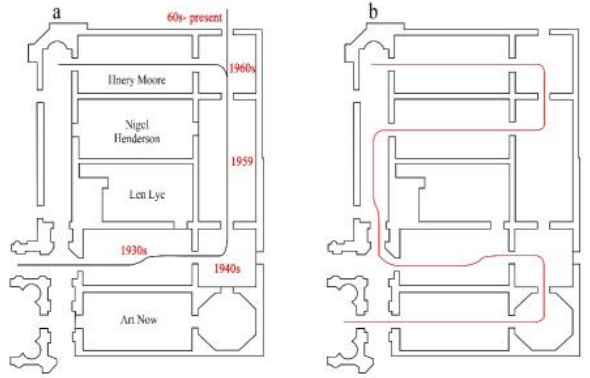

Figure 18a: The arrangement of displays in route 'British Art 1930-now'; Figure 18b: Ideal Hamiltonian path with only one room closed

Similarly to the main building of the National Gallery, the Tate Britain has a grid-like structure of integration centres with the main integration centre on axis and sub-centres on the west, south and east sides of the building (Figure 19a). The one-way strategy for reopening has changed this spatial structure to two c-type sequences that cover the main centres only. In terms of spatial types, like the National Gallery, the Tate Britain has limited the number of $d$-spaces to those located on the main axis (Figure 20). Once visitors make a choice of route along this axis, they can only finish a sequence and get back to it. These changes illustrate that after reopening the Tate Britain comes close to Huang's model of modern museums with a 'deep integration core and strong sequence' (2006). Each sub-cycle in the Tate Britain is assigned a historical theme which is enhanced by the sequenced spaces. The style of the visiting experience thus, changes from one where the rings of circulation guide the encounter of the visitors with the artworks to one where a pre-decided sequence and educational message structure the visit, that is, from a spatially driven model to a conceptual model of exhibition.
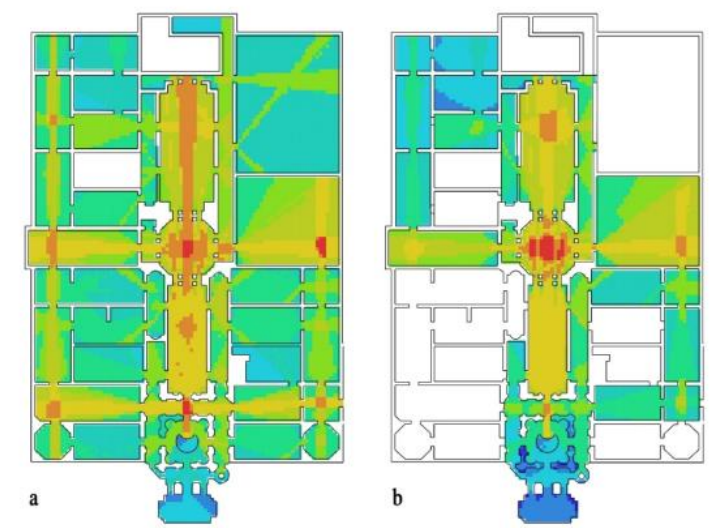

Figure 19: VGA of Tate Britain. (a) before reopening; (b) after reopening 

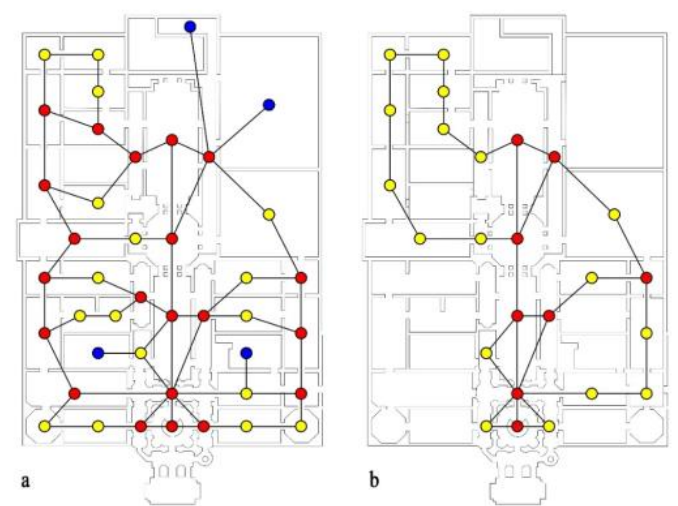

Figure 20: Unjustified graphs and space types. (a) before reopening; (b) after reopening

\subsection{Tate Modern}

A lot of museums have put lines all over the floor and, you know, they kind of look like supermarkets. So what we've done at Tate Modern is its minimal signage and where it is you really have to follow it...... It is quite a clear message about how to negotiate the building. We found that our spaces are very suited to this kind of operation (Director of Tate Modern, Frances Morris, Interview with The Voice Newspaper, August 2020).

Compared to the National Gallery and the Tate Britain, the Tate Modern has introduced fewer changes in order to construct a one-way circulation pattern. With a display that does not follow a historical scheme, the Tate Modern has greater flexibility than other museums to alter the curatorial message by changing the visiting sequence. The western display rooms for example are visited in a reversed way than in the original plan. (Figure 21). The distribution of visual integration after reopening is not significantly different to that of

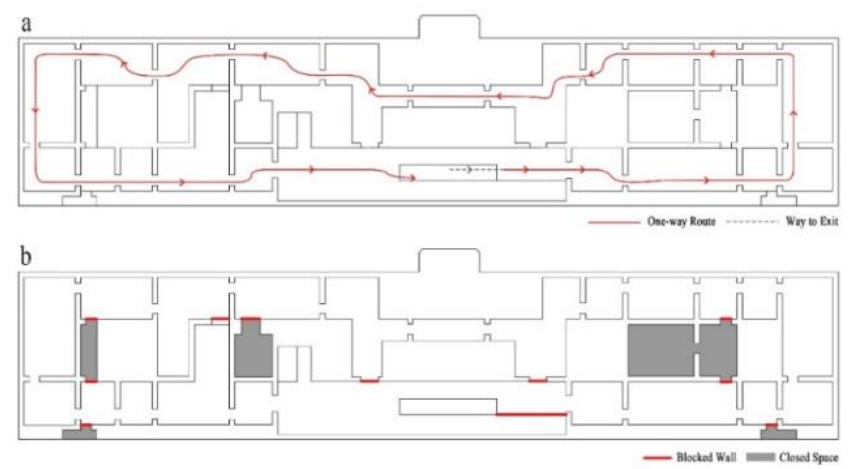

Figure 21: a. One-way routes in Tate Modern; b. blocked doorways and rooms

the original layout, apart from the decreased integration values in the north part (Figure 22). Looking at the changes of spatial types, after applying the one-way strategy all spaces are c-spaces (Figure 23). In fact, among all the museums we have investigated, the Tate Modern is the only one that has successfully achieved the Hamiltonian cycle.
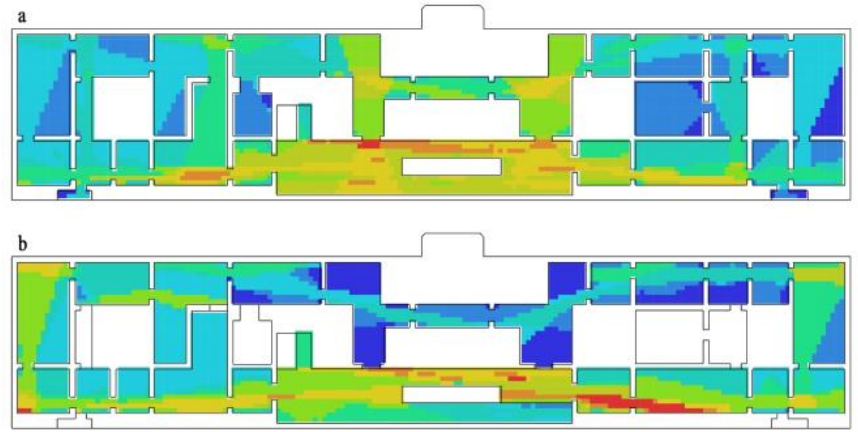

Figure 22: VGA of Tate Modern. (a) before reopening; (b) after reopening 

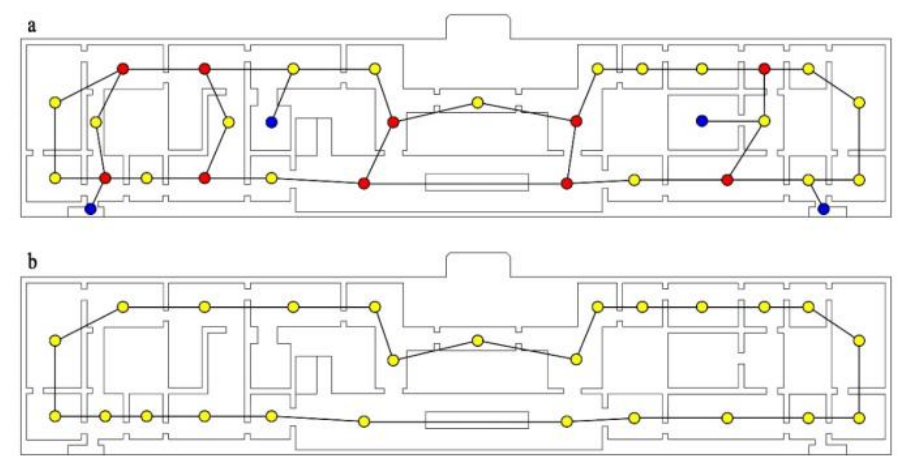

Figure 23: Unjustified graph of Tate Modern. (a) before reopening; (b) after reopening

\subsection{The Wallace Collection}

Previously owned by a private collector, the Wallace Collection is now a national museum exhibiting European collections from the 15th to the 19th century. The building is much smaller compared to the other buildings, and has a large main-sequence intersecting with an inner sub-cycle (Figure 24a). The museum has closed only three spaces and assigned a single-directional path starting from the entrance and finishing at the exit in the west side (Figure 24b). As a consequence, the $d$-spaces before reopening are turned into c-spaces (Figure 24e, f). Due to the small size of the collection, displays are simply arranged by themes such as decorative arts, French paintings and furniture. Similarly to the Tate Modern, the arrangement of displays in the Wallace Collection does not follow any narrative minimising the effect of the one-way route on visitors' experience.
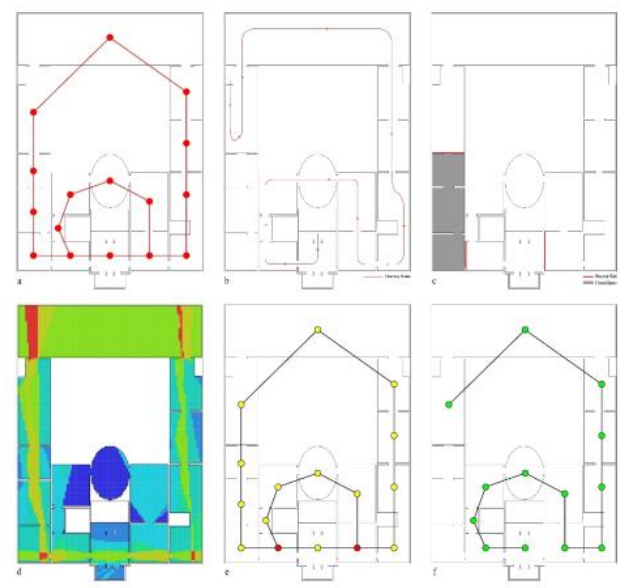

Figure 24: Analytical graphs of the Wallace Collection. (a) unjustified graph of initial layout; (b) one-way path after reopening; (c) blocked doorways and rooms; (d) VGA before reopening; (e) spatial types before reopening; ( $f$ ) spatial types after reopening

\section{Traversability of the four British art museums}

Traversability is a crucial property of layouts for its close connection with the Hamiltonian path where in its highest values it allows visiting as many gallery spaces as possible and omitting as few rooms as possible. Hillier has associated the c-type and d-type structure with high values of traversability and Hamiltonicity (2019), as opposed to the a-type and b-type of structure that have the lowest traversability values. Here we test this model with the layouts of the museums before and after reopening, and evaluate their strategy of circulation based on the capacity of the spatial structure to provide the closest to the ideal Hamiltonian path. The Wallace Collection is not included in the comparison as the size of this museum is smaller than the others. Table 4 presents the traversability value of the four British museums before the pandemic. Despite their differences in terms of spatial properties and exhibition themes, most of the museums have similar traversability value between $0.75-0.78$. Surprisingly, the Sainsbury Wing in spite of its grid-like layout has the lowest value at 0.67 . As shown in Figure 25a, the Hamiltonian cycle in the Sainsbury Wing requires omitting the rooms on central axis. The Tate Britain has the highest traversability value among all layouts, with only $22 \%$ of spaces closed for the Hamiltonian path. 


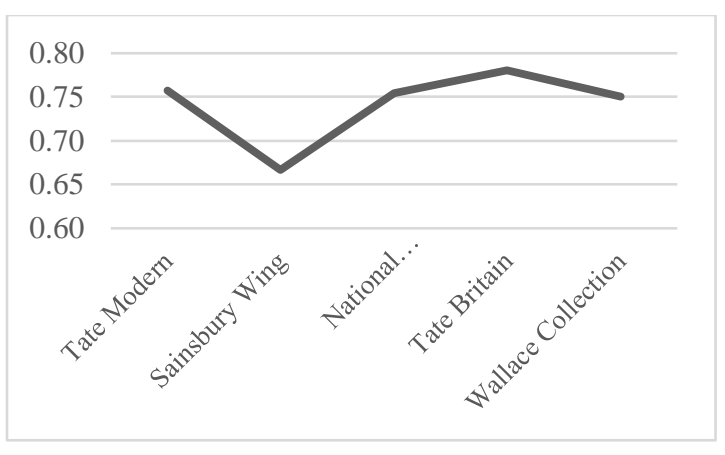

Table 4: Traversability of the British art museums before reopening

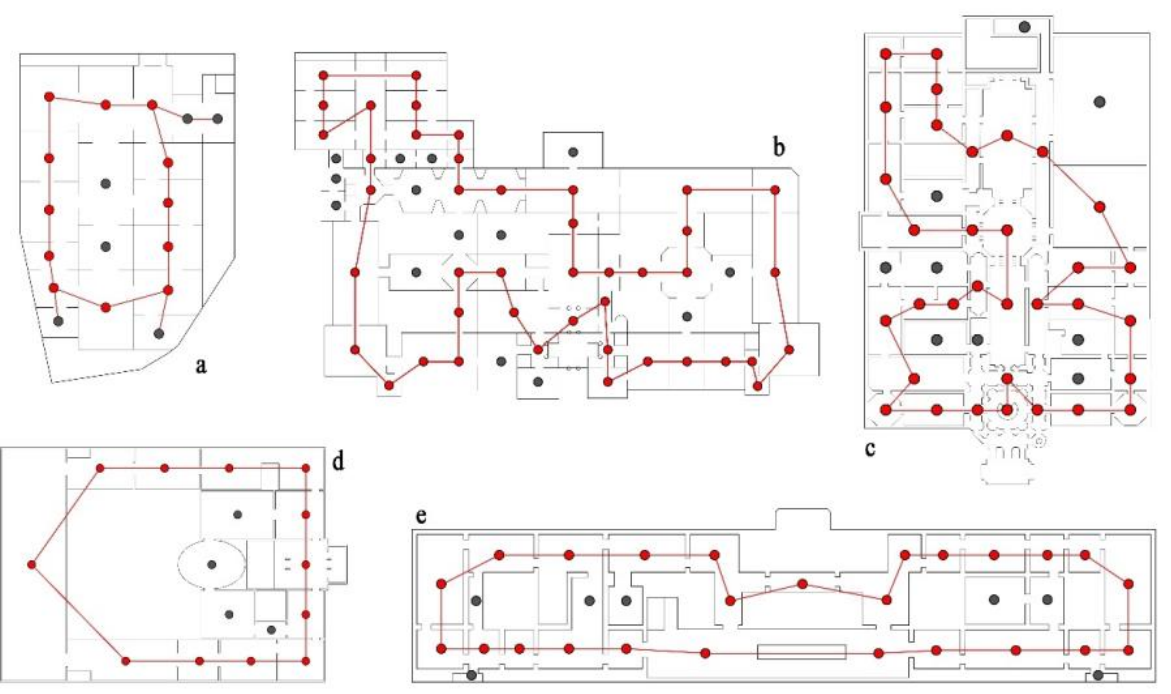

Figure 25: Hamiltonian Cycle of the British art museums. (a) Sainsbury Wing; (b) main building of the National Gallery; (c) Tate Britain; (d) the Wallace Collection; (e) Tate Modern

Figure 27 shows that that layouts with a higher proportion of $d$-spaces over the total number of spaces in the layout tend to have the highest traversability values $\left(R^{2}=0.8359\right)$, confirming Hillier's proposal about $d$ structures possessing high levels of traversability. In contrast to Hillier's model about c-spaces, the correlation between the proportion of $c$-spaces and traversability values is weak $\left(R^{2}=0.1889\right)$. Based on the suggestion that the balance between c-spaces and d-spaces is the crucial factor influencing visiting experience (Hillier and Tzortzi, 2006), we calculated the ratio of the number of c-spaces to $d$-spaces and find that there is a high negative correlation with traversability $\left(R^{2}=0.8371\right)$. In other words, the higher the number of $d$-spaces compared to c-spaces, the better museums can adjust to a Hamiltonian path, and to the one-way strategy. It is noted that this is a preliminary study and more cases should be added to the sample for a statistically reliable result. However, it provides the first test of Hillier's theoretical model in the 2019 paper.

Does this result illustrate that as long as museums increase the interconnectivity of spaces, they can get better levels of traversability? In order to answer this question, we look at the correlation between the ratio of no of connections (doorways) to the number of nodes (spaces) within the layouts and traversability (Figure 27d). The weak correlation between the two variables $\left(R^{2}=0.3395\right)$ suggests that simply enhancing spatial interconnectivity by opening more doorways does not lead to the increase of traversability value. It is rather the arrangement of $d$-spaces and their relation to the rest of the spaces in that contributes to high traversability values. A detailed discussion is provided in the following session with a focus on the c- and dstructures in museums. 


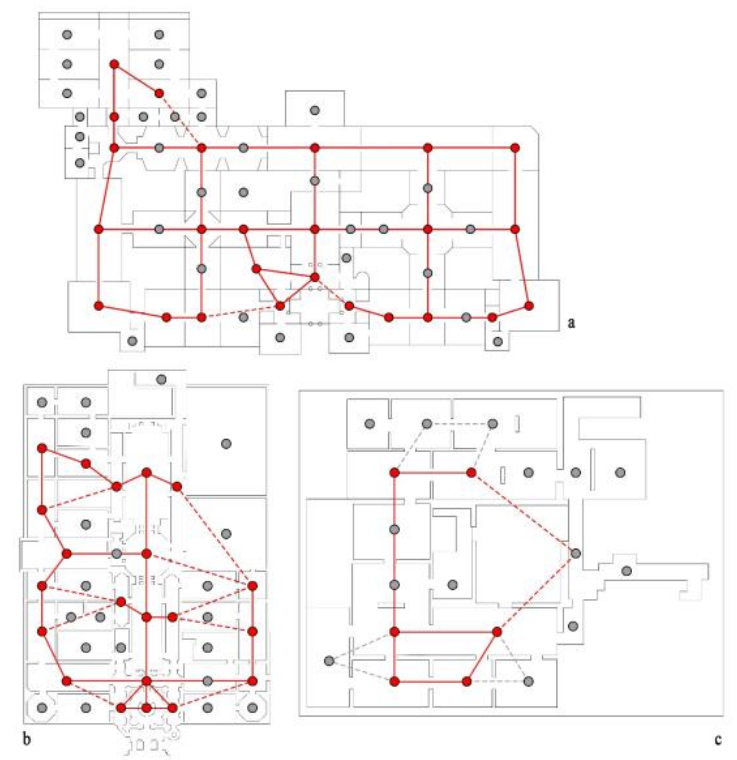

Figure 26: Unjustified graph showing connections between d-spaces. (a) the National Gallery - main building; (b) the Tate Britain (c) the fifth floor of MoMA in 2005

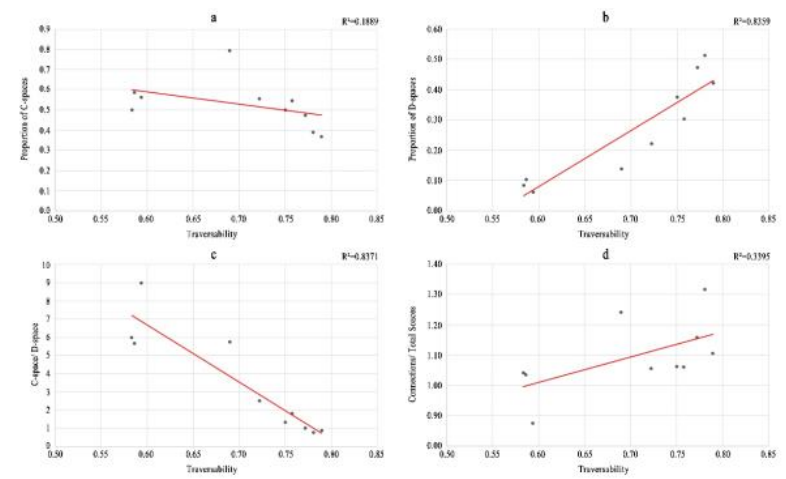

Figure 27: Correlations between spatial properties and traversability. (a) proportion of c-spaces $\left(R^{2}=0.1889\right)$; (b) proportion of $d$-spaces $\left(R^{2}=0.8359\right) ;(c)$ quotient of the number of c-spaces and d-spaces $\left(R^{2}=0.8371\right)$; (d) quotient of the number of connections between spaces and the total number of spaces $\left(R^{2}=0.3395\right)$

\section{Discussion}

\subsection{Spatial structure and traversability}

Hillier's suggestion that c- and d-structures have the highest levels of traversability at 1 (2019) means that in a spatial layout with a cyclical form or a grid form there is no need to close any connections between spaces in order to obtain a Hamiltonian path. In practice, the spatial layout of large museums is more complicated than Hillier's model containing dead-end spaces and sub-cycles. Among the museums we have investigated, the fifth floor of the MoMA in its 2005 version and the Tate Britain have the highest levels of traversability at 0.79 , and 0.78 respectively. We suggest that while the 2005 MoMA illustrates how the spatial organization of a complex c-structure can have high levels of traversability of a small number of paths only, the Tate Britain has higher levels of adaptability to strategies specifying more than one one-way route.

Psarra proposes (Psarra et all., 2007; Psarra, 2009) that the expansion of MoMA in 2005 expressed Alfred Bar's conceptual organisation of Modern Art as a dual trajectory (the 'rational' and 'intuitional' thematic lines) through the spatial arrangement which interconnects sub-cycles, which showcase the rational theme, with the main sequence, presenting the intuitional narrative line. Sub-cycles are locally organised by $d$-spaces enabling visitors to take a detour from and return to the main sequence (Figure 26c). As for the Tate Britain - the dstructured museum as defined by Hillier (ibid.) - a clear global network of $d$-spaces, consisting of centres and sub-centres, covers the whole layout with intervening c-spaces in between. In both buildings, $d$-spaces play an important role in constructing the global structure as well as connecting global-scale and local-scale movement. Appropriate numbers of $d$-spaces and their relational logic with c-spaces and the rest of the spaces 
in spatial design will not only give rise to social co-presence and encounter in the process of visiting, as Hillier suggests (Hillier, 2019), but also increase the adaptability of the layout to accommodating Hamiltonian paths.

\subsection{The effect of spatial system}

The different implications of the one-way strategy in the British museums illustrate the importance of the spatial system in the reopening. The main building of the National Gallery and the Tate Britain implement the largest number of changes in order to control people's movement due to the pandemic. Figure 29 shows a schematic diagram of the spatial structure of the two museums before reopening. They both consists of a three-layered spatial system consisting of a network of main centres and sub-centres distributing movement to local spaces. However, the sub-centres in the National Gallery are situated between the main centres and the local spaces found in the periphery. In contrast, in the Tate Britain the main centres transfer movement to the sub-centres at the edges of the building. Since in the main building of the National Gallery the connections between its main centre and sub-centres are blocked, the relation between global-scale and local-scale movement is weakened. As a result, the spatial layout becomes less intelligible. On the other hand, in both buildings, although the sub-centres change from d-spaces to c-spaces (Figure 16, 20) losing their structural role in the system, the main centre retains its power in distributing movement since it has direct connections with local spaces.

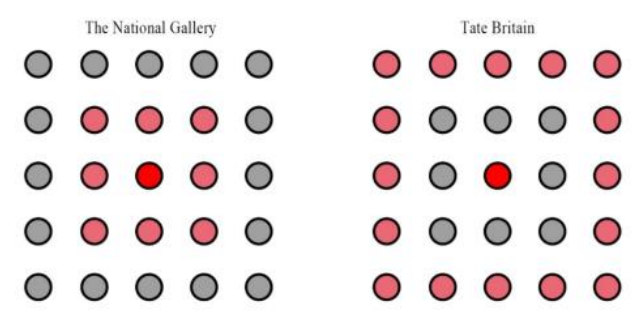

Figure 29: Schematic diagrams of the spatial structure of the National Gallery and Tate Britain's layouts before reopening

\subsection{The effect of the display arrangement}

The curatorial intention about the exhibition arrangement in the British art museums also plays an important role in the modification of spatial configuration in the reopening strategies. This study proposes that there are two curatorial factors that influence the architectural experience of museums and the spatial changes for reopening: whether the narrative has coherence (chronological, thematic or otherwise) and if the meaning of the display is pre-given (Figure 30). As suggested by museum scholars (Tzortzi, 2007; Psarra, 2009), the visitors' engagement with exhibitions is more likely to be varied in museums which encourage spatial exploration. Based on the four museums studied here, we argue that the original layout of the Tate Britain, the National Gallery and the 2005 layout of the MoMA provide visitors with potential for individual experience. On the other hand, the limited number of alternative sequences in the Tate Modern, the MoMA 2019 and the Sainsbury Wing construct an educational and aesthetic experience that is pre-given.

Although shifting to linear sequences with a chronological narrative after reopening, the Tate Britain and the main building of the National Gallery present different approaches to adapting to changes due to the pandemic. Sequenced narratives have existed in Tate Britain before COVID-19, but were weakened by the spatial configuration which encouraged self-exploration. As previously explained, the changes that happened in the Tate Britain are mainly directed by the chosen narratives of the exhibition sequences, since the museum blocks more spatial connections than a Hamiltonian cycle needs (Figure 20). On the other hand, having initially no sequenced narrative, the one-way routes in the National Gallery's main building creates new narratives. Since the one-way strategy eliminates free exploration, all British art museums are now offering pre-designed visiting experiences based on the curators' intentions. 


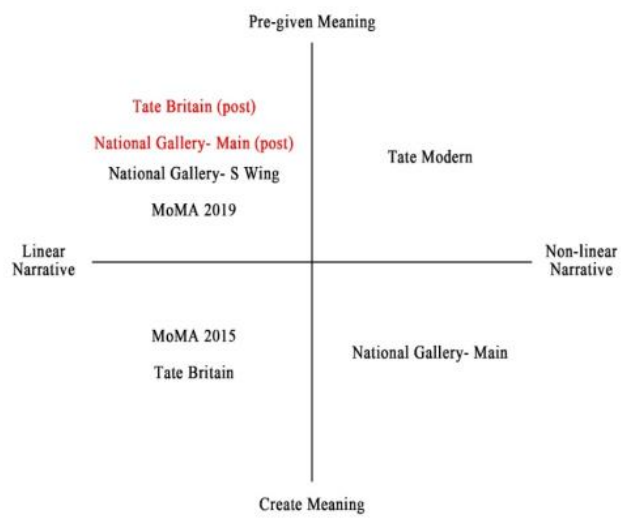

Figure 30: Types of display arrangement (based on Tzortzi's diagram, 2007)

\subsection{A dynamic strategy instead of one-way circulation}

There might be alternative solutions to the one-way strategy that British museums are applying, controlling congestion through curatorial and technological interventions on route choices. The National Gallery's main building for instance, is expected to have a more intelligible organization of movement patterns if its spatial interconnectivity is not weakened and visitors are guided by a dynamic minimal system of instructions provided through audio-equipment or signage in the main centres and sub-centres. This study suggests that the distribution of $d$-spaces inside the layout and the connection between global and local spatial network are the two factors that determine whether the spatial configuration of museums is able to accommodate such dynamic strategy. Even in the future when social distancing is no longer important, the joint operation of spatial configuration and curatorial interventions, such as customised visiting routes and defining no-go zones where the density of people has reached the top line, will still contribute to improving over-crowdedness and other potentially undesirable situations (Seo and Ahn, 2010; Yoshimura et al., 2014; Tsiropoulou et al., 2017).

\subsection{The spatial culture of art museums in post-COVID-19}

It is arguable whether the relationship between museums and visitors is going to have a permanent change because of the pandemic. However, the responses of the four British art museums reflect in some sense Huang's proposal that the role of museums is gradually transforming from educational to commercial environments. The powerful spatial control at the global level and the strong sequences with pre-given meaning in the Tate Britain provide visitors with an experience that has been pre-structured before they even begin their exploration inside the building. While museums are changing both spatially and curatorially, visitors are likely to be more knowledgeable as well, since virtual museums are recently becoming popular and people can explore them online before they pay the actual visit. Whether the museums will be the 'machine of showing art' (Serota, 1995) or 'civil education authorities' (Hulten, 1974), it is necessary for curators to understand the transformation of spatial cultures in terms of the new spatial-curatorial arrangements and the new attitudes of the visiting public.

\section{Conclusion}

This study has investigated the influence that the outbreak of COVID-19 has brought on four British art museums and one American art museum. While the spatial effect on movement patterns has been emphasized by curators around the world for the control of the virus transmission, British art museums chose the one-way circulation strategy for their reopening. Based on the findings from the analysis of spatial changes in these museums, a spatial-curatorial evaluation system is proposed for examining the current reopening approaches and the likely effects to the future spatial design of museums.

The study has provided a first test of Hillier's comparative model of spatial structures, confirming that dstructures achieve high levels of traversability. The $d$-structure is the determinant factor that not only influences spatial exploration and navigation, but also plays an important role in the social and aesthetic construction of meaning alongside the exhibition arrangement. We have found that museums with $d$ structures such as the National Gallery and the Tate Britain consist of a grid-like system of main centres and sub-centres that distributes movement to the local spaces. Similarly to the dual-network of urban streets (Hillier, 2003), we propose that there is also a dual-, sometimes three-layered, network in the spatial layout of 
museums. While the $d$-structure serves as the foreground system and the c-, b- and a- spaces as the local system, the way in which global and local structures interconnect with each other affects the exploration patterns of visitors and the adaptability of museums to restrictions introduced by the pandemic. Associated with spatial properties, the display narrative also carries the potential to affect the organisation of routes limiting or optimising the available sequences to define the spatial, educational and aesthetic experience. Different from Hillier's approach that focuses only on the spatial structure of the Tate Britain for the generation of social encounters, this study argues that what really matters is the cooperation between curatorial approaches to narrative and spatial networks. With the proper curatorial-spatial arrangement, museums which have predominantly a c-structure in their layout, such as the fifth floor of MoMA 2005, can also give rise to social meaning and have capability to facing the necessary spatial changes.

There are two limitations to this study. First, the art museums we investigated are all large museums with a considerable amount of displays. Therefore, a pure c-structured spatial layout is not likely to be seen in these museums. In fact, small art museums which often have only one sequenced route do not need to adapt to many spatial changes even if there are no d-spaces in their spatial configuration. The Wallace Collection in London for example, has traversability value at 0.75 , successfully choosing the ideal one-way route because of its initial single sequence and the small a number of collections that cannot or do not need to add up to a coherent narrative. The second limitation in this work is the lack of observation studies collecting empirical data during the reopening of museums. A future study should test the theoretical model with movement data from field work, identifying how visitors choose routes in the south end of Sainsbury Wing and how people in the main building of the National Gallery and the Tate Britain use the gathering space along the main axis after reopening. 


\section{References}

Agostino, D., Arnaboldi, M. and Lema, M.D., 2020. 'New development: COVID-19 as an accelerator of digital transformation in public service delivery'. Public Money \& Management, pp.1-4.

Capillé, C. and Psarra, S., 2014. 'Space and planned informality: Strong and weak programme categorisation in public learning environments.' A/Z ITU Journal of the Faculty of Architecture, 11(2), pp.9-29.

Choi, Y.K., 1999. 'The morphology of exploration and encounter in museum layouts.' Environment and Planning B: Planning and Design, 26(2), pp.241-250.

Hillier, B., 1996. Space is the machine. Cambridge: Cambridge University Press.

Hillier, B., 2019, July. 'Structure or: Does Space Syntax Need to Radically Extend Its Theory of Spatial Configuration?.' In Proceedings of the 12th International Space Syntax Symposium. Beijing JiaoTong University, Beijing (pp.0).

Hillier, B. and Hanson, J., 1989. The social logic of space. Cambridge: Cambridge University press.

Hillier, B. and Tzortzi, K., 2006. Space syntax: the language of museum space. Mc Donald, S. (ed.) A companion to museum studies, Malden MA: Blackwell, pp.282-301.

Hillier, B., Major, M.D., Desyllas, J., Karimi, K., Campos, B. and Stonor, T., 1996. 'Tate Gallery, Millbank: A study of the existing layout and new masterplan proposal.' Technical report, Bartlett School of Graduate Studies, University College London, London.

Honey-Roses, J., Anguelovski, I., Bohigas, J., Chireh, V., Daher, C., Konijnendijk, C., Litt, J., Mawani, V., McCall, M., Orellana, A. and Oscilowicz, E., 2020. 'The impact of COVID-19 on public space: a review of the emerging questions.' [online]. Available at: https://osf.io/rf7xa/ (Accessed: 22 September 2020).

Huang, H., 2001, May. 'The spatialization of knowledge and social relationships.' In Proceedings of the Third International Space Syntax Symposium, Georgia Institute of Technology. Atlanta GA (pp. 43-1).

Huang, H., 2006, July., 'The embodiment of the social roles of modern museums-A study on the space and body in the modern museums.' In International Committee for Museum Management 2006 Symposium, Chinese Association of Museums, Beijing.

Hulten, P., 1974. 'Beaubourg et son musée où explosera la vie [Beaubourg and Its Museum Where Life Will Explode].' Réalités, no. 337.

Koch, D., Stein, J. (2012), 'Decomposing Programmes-Recoding Hospital Work with Spatially Syntactic Information', $8^{\text {th }}$ ISS Symposium, Chile, 85.41:1-20.

Lazaridou, A. and Psarra, S, 2015, July. 'Experiencing three-dimensional museum environments: An investigation of the Ashmolean Museum and the Museum of Scotland.' In Proceedings of the $10^{\text {th }}$ International Space Syntax Symposium, University College London (pp. 025.1-25).

Lazaridou, A. and Psarra, S., 2017, July. 'Spatial navigation in real and virtual multi-level museums'. In Proceedings of the 11th International Space Syntax Symposium, Instituto Superior Tecnico, Lisbon (pp. 14-1).

Peponis, J., and Hedin, J., 1982. 'The spatial layout of theories in the Natural History Museum'. 9H, 3, pp.21-25.

Psarra, S., 2009. Architecture and Narrative: The formation of space and cultural meaning. London: Routledge.

Psarra, S., Wineman, J., Xu, Y. and Kaynar, I., 2007. 'Tracing the Modern - Architecture and Narrative Content at the Museum of Modern Art (MoMA) and its latest Expansion', Proceedings of the International Space Syntax Symposium VI, Istanbul Technical University, Istanbul, Turkey. 70.1-16.

Psarra, S. and Grajewski, T., 2000. 'Architecture, narrative and promenade in Benson+ Forsyth's Museum of Scotland.' ARQ: Architectural Research Quarterly, 4(2), pp.123-136.

Sailer, K., Penn, A. (2009), 'Spatiality and Transpatiality in Work Place Environments', $7^{\text {th }}$ ISS Symposium, Stockholm, 095:1-11.

Seo, Y. and Ahn, J., 2010, September. 'On Reducing the Impact of Exceptional Conditions on Museum Sightseeing Crowdedness Control Mechanisms.' In International Conference on Security-Enriched Urban Computing and Smart Grid, Springer, Berlin, Heidelberg (pp. 206-212).

Serota, N., 1998. 'The New Tate Gallery of Modern Art.' Casabella, 661, p.14.

Stavroulaki, G. and Peponis, J., 2003, June. 'The spatial construction of seeing at Castelvecchio'. In Proceedings of the 4th International Space Syntax Symposium, University College London, London (pp. 66-1).

Tsiropoulou, E.E., Thanou, A. and Papavassiliou, S., 2017. 'Quality of experience-based museum touring: A human in the loop approach.' Social Network Analysis and Mining, 7(1), p.33.

Tzortzi, K., 2003, June. 'An approach of the microstructure of the gallery space: The case of the Sainsbury Wing.' In Proceedings of the 4th International Space Syntax Symposium, University College London, London (pp. 67-1).

Tzortzi, K., 2007, June. 'Museum building design and exhibition layout.' In Proceedings of the 6th International Space Syntax Symposium, Istanbul Technical University, Istanbul (Vol. 1215, p. 072). 
Tzortzi, K., 2011. 'Space: interconnecting museology and architecture.' The Journal of Space Syntax, 2(1), pp.2653.

Wineman, J.D. and Peponis, J., 2010. 'Constructing spatial meaning: Spatial affordances in museum design'. Environment and Behavior, 42(1), pp.86-109.

Yoshimura, Y., Sobolevsky, S., Ratti, C., Girardin, F., Carrascal, J.P., Blat, J. and Sinatra, R., 2014. An analysis of visitors' behavior in the Louvre Museum: A study using Bluetooth data'. Environment and Planning B: Planning and Design, 41(6), pp.1113-1131. 